\title{
A Role for Topoisomerase I in Fusarium graminearum and F. culmorum Pathogenesis and Sporulation
}

\author{
Thomas K. Baldwin, Martin Urban, Neil Brown, and Kim E. Hammond-Kosack \\ Centre for Sustainable Pest and Disease Management, Department of Plant Pathology and Microbiology, Rothamsted \\ Research, Hertfordshire, AL5 2JQ, U.K.
}

Submitted 17 September 2009. Accepted 20 January 2010.

Fusarium graminearum and $F$. culmorum are the causal agents of Fusarium ear blight (FEB) in wheat. A forward genetics approach was taken to discover novel pathogenicity genes in the genome of $\boldsymbol{F}$. graminearum. A library of transformants created by random plasmid insertional mutagenesis was screened on wheat ears for virulence defects. Plasmid rescue on one of the reduced-virulence mutants revealed a single-copy plasmid insertion in the gene coding for the DNA interacting enzyme, topoisomerase I. Targeted topoisomerase I gene-deletion mutants were created in strains of both $F$. graminearum and $F$. culmorum. The top1 mutants of both species exhibited greatly reduced virulence in wheat ear infection assays (GO:0009405 and GO:0044145). Detailed microscopy analyses revealed that top1 hyphal growth was restricted to palea tissue whereas host responses were discernable $1,000 \mu \mathrm{m}$ further away in the rachis node. Asexual sporulation was reduced in the $F$. graminearum mutants and was absent from the $F$. culmorum mutants. The $F$. graminearum mutant did not develop sexual spores when subjected to an in vitro perithecia production assay. During in vitro growth, the top1 mutants of both species were still able to produce the trichothecene mycotoxin, deoxynivalenol.

Topoisomerases are enzymes which relax supercoiled DNA, enabling many basic cellular processes to occur, such as transcription, replication, and recombination (Wang 2002). The crystal structures of human topoisomerase I and topoisomerase I-DNA complexes have been determined by X-ray crystallography (Redinbo et al. 1998). Topoisomerases are classed as either type I or type II, depending on whether they mediate relaxation of DNA supercoils by creating either single- or double-strand breaks (type I or II, respectively) in the phosphodiester backbone of DNA (Champoux 2001). In the genome of Saccharomyces cerevisiae, one type II (TOP2) and two type I (TOP1 and TOP3) topoisomerases have been identified and functionally characterized (Hirschman et al. 2006). Disruption of the TOPl gene in S. cerevisiae, a eukaryotic type I (type IB) topoisomerase which can relax negatively and positively su-

Current address of T. K. Baldwin: INRA-Rennes, UMR BiO3P, 35653 Le Rheu cedex, France.

Corresponding author: K. E. Hammond-Kosack; E-mail: kim.hammondkosack@bbsrc.ac.uk

Sequence data from this article can be found in the EMBL/GenBank data libraries under accession number FJ938238.

* The $\boldsymbol{e}$-Xtra logo stands for "electronic extra" and indicates that nine supplementary figures and three supplementary tables are available online. percoiled DNA, demonstrated that the gene is not essential for yeast viability (Goto and Wang 1985). The doubling time of the $S$. cerevisiae top 1 mutant was approximately $30 \%$ longer than the wild type (Thrash et al. 1985). Similar studies demonstrated that TOP1 is not essential for the growth of the fission yeast Schizosaccharomyces pombe (Uemura et al. 1987). Disruption of the second type I topoisomerase in Saccharomyces cerevisiae (TOP3), a bacterial type I (type IA) topoisomerase which also creates single-strand breaks but only in negatively supercoiled DNA, revealed that completion of meiosis is dependent on a functional TOP3 enzyme. Therefore, homozygous yeast top 3 mutants were unable to form ascospores (Gangloff et al. 1999). Experiments with the yeast type II topoisomerase, which creates ATP-dependent double-strand breaks in DNA, revealed that TOP2 is an essential gene (Goto and Wang 1985).

Functional analysis of the TOP1 gene in the Basidiomycete plant pathogen Ustilago maydis revealed that the gene is not essential for vegetative growth but the top 1 mutant does exhibit a pigmentation defect (Gerhold et al. 1994). The U. maydis topl mutant was not assessed for virulence defects in any pathogenicity assays. No other functional analyses of topoisomerases in plant pathogens have been published, although studies of the role of TOP1 in animal pathogenesis have been published for the fungi Candida albicans and Cryptococcus neoformans (Jiang et al. 1997; Del Poeta et al. 1999b). Single and double TOP1 gene disruption strains of the diploid pathogenic yeast Candida albicans were created. Both strains were tested alongside wild-type controls by injecting cell suspensions into mouse tail veins and assessing virulence by quantifying kidney colonization. The single mutants were slightly reduced in virulence whereas the double mutants showed greatly reduced virulence versus the wild-type strain (Jiang et al. 1997). Interestingly, TOP 1 appears to be an essential gene in Cryptococcus neoformans. Only ectopic transformants were recovered from several experiments designed to create a top 1 mutant. However, when a second copy of the TOP 1 gene under an inducible promoter was introduced into the $C$. neoformans genome, the original TOPl gene was successfully deleted (Del Poeta et al. 1999b).

Fusarium ear blight (FEB) disease, also known as Fusarium head scab in the United States, is caused by up to 17 related Fusarium spp. and occurs on all Gramineae spp., including the economically important crops wheat, barley, rice, and maize (Parry et al. 1995). This disease leads to reductions in grain yield and quality. Also, the grain becomes contaminated with harmful trichothecene mycotoxins. Within the United Kingdom, the main causal organisms include Fusarium culmorum and $F$. graminearum. In the United States, $F$. graminearum is the dominant species, where it causes ear 
and stalk rot of maize. The incidence of $F$. graminearum infection has also increased in European countries. In the Netherlands, morphological studies undertaken during the 1980s and 1990 s showed that $F$. culmorum was the dominant species. However, a study of Dutch field isolates collected in 2000-01, using Fusarium spp.-specific polymerase chain reaction (PCR) primers, indicated that the dominant species is now F. graminearum (Waalwijk et al. 2003). There have been no studies reported to date that have compared the pathogenicity genes required by $F$. culmorum and $F$. graminearum to cause disease on wheat ears. The efficacy of chemical fungicides, natural sources of resistance, and transgenic defense proteins could be affected by any differences between the two species.

In this study, the $F$. graminearum strain $\mathrm{PH}-1$ was used to create a random insertional transformant library using a linearized plasmid technique. This strain represents the main genetic lineage distributed throughout the world (O'Donnell et al. 2000). The genome of this strain has been sequenced, anchored to a genetic map, and annotated by both the Broad Institute and Munich Information Center for Protein Sequences (MIPS) (Cuomo et al. 2007). The PH-1 strain of $F$. graminearum was originally chosen for the genome sequencing project because it sporulates well in vitro; produces high levels of mycotoxin (>300 ppm); and is pathogenic to wheat, barley, and maize (Cuomo et al. 2007). The transformant library generated for this study was screened on susceptible wheat ears and three reduced-virulence mutants were identified. Plasmid rescue was used to clone the disrupted gene of one of these reduced-virulence mutants. The role of the gene identified, topoisomerase I, in pathogenicity and sporulation was verified in $F$. graminearum and F. culmorum by targeted gene deletion. Various phenotypes of gene deletion strains of both Fusarium spp. were compared and contrasted with wild-type strains growing in planta and in vitro.

\section{RESULTS}

\section{Isolation of the topoisomerase 1 mutant.}

A fungal protoplast-plasmid insertional mutagenesis approach was used to create a library of random plasmid insertion transformants. From a total of 90 stable $F$. graminearum hygromycin-resistant transformants, 3 were recovered which exhibited severely reduced virulence on susceptible wheat ears. DNA gel blot analyses revealed that the transformant TB3 contained a single-copy insertion (Supplementary Fig. 1). A series of plasmid rescue and sequencing experiments revealed that the integration of the pHyg1.4 plasmid had occurred within the locus FGSG_06874.3 situated on chromosome 4 (Supplementary Fig. 2). This locus is predicted to code for a topoisomerase I enzyme. BLASTP analyses revealed that the predicted $F$. graminearum protein had the highest identity (48\%) with $S$. cerevisiae TOP1. Therefore, the FGSG_06874.3 locus was named FgTOPI. The disease phenotypes caused by the wildtype PH-1 strain and the transformant TB3 are shown in Figure $1 \mathrm{~A}$ and $\mathrm{B}$, respectively.

\section{Identification and sequencing of the TOP1 homologue in F. culmorum.}

The presence of a TOP 1 homologue in the genome of F. culmorum was confirmed by PCR with primers designed to the neighboring genes predicted on the $\mathrm{PH}-1$ genome sequence. Two overlapping PCR products were amplified from the genomic DNA of three F. culmorum strains of U.K. origin; namely, UK99, 98/11, and 97/7. Further primers were designed based on the PH-1 genome sequence for sequencing the PCR products amplified from the $F$. culmorum genomic DNA. The $F$. culmorum TOP 1 homologue $(F c T O P 1)$ and flanking regions were sequenced on both the positive and negative DNA strands in overlapping 700- to 800-bp lengths, resulting in at least two times coverage across the locus. This FcTOPl sequence was deposited at the National Center for Biotechnology Information (FJ938238). The success of this experimental strategy indicates that gene order and gene orientation was conserved in this region of the two Fusarium genomes.

Molecular phylogeny of eukaryotic topoisomerase I proteins.

The topoisomerase I gene is conserved in all the eukaryotic genomes sequenced to date. An alignment of the predicted TOP1 protein sequences from several fungal, animal, plant, and protist species was created using the CLUSTALW algorithm. The predicted $F$. graminearum TOP 2 and TOP3 protein sequences were also included in the alignment. The amino acid alignment was used to create a phylogenetic tree of the TOP1 proteins (Supplementary Fig. 3). It is clear from this tree that the TOP2 and TOP3 proteins are unrelated to each other and to the cluster of TOP1 proteins analyzed in this alignment. As expected, the TOP1 proteins are grouped according to the taxonomy of the species in the alignment. The TOP1 proteins of Ascomycete, animal, plant, and protist species form individual clades. The Ascomycete clade is divided further into TOP1 sequences from filamentous fungi (clades A, B, and C) and from yeasts (clade D). There is a lack of clustering evident according to the lifestyle of the species. For example, the TOP1 protein of the nonpathogenic Trichoderma reesei is placed close to the TOP1 proteins of the plant-pathogenic Fusarium spp. (clade A). Also, the $U$. maydis TOP1 protein appears to be significantly different from all of the other TOP1 proteins in the tree, including those from the Basidiomycetes $C$. neoformans and $C$. cinereus.

\section{Targeted deletion of $F g T O P 1$ and $F c T O P 1$.}

The role of the FgTOP1 and FCTOPI genes in pathogenicity was verified by targeted gene deletion in wild-type strains of $F$. graminearum (PH-1) and F. culmorum (UK99). From nine $F$. graminearum transformants selected for further analysis, three were verified by DNA gel blot analysis to correspond to TOP1 deletants lacking additional ectopic plasmid insertions (Supplementary Fig. 4A and B). From five F. culmorum transformants selected, PCR diagnostic tests revealed that the FCTOP1 gene was deleted from three transformants (data not shown). DNA gel blots revealed two topl gene deletion mutants which contained no ectopic insertions. During DNA extraction, obvious color differences between transformants were observed when the freeze-dried and finely ground fungal mycelia were resuspended in cetyltrimethylammonium bromide (CTAB) lysis buffer. The light-colored extractions in both species corresponded to strains which lacked the TOPl gene (Supplementary Fig. 5).

\section{The inhibitory effects of the TOP1 specific drug camptothecin.}

Camptothecin (CPT) has been demonstrated to be a cytotoxic compound which specifically interacts with the topoisomerase I enzyme (Redinbo et al. 1998). The growth of two topl mutants for each of the Fusarium spp. was compared with their wild-type progenitor strains, as well as the original $F$. graminearum mutant TB3 (Fg top 1::pHyg 1.4), in the presence of camptothecin. The addition of CPT to synthetic nutrient-poor agar (SNA) plates resulted in a 50\% reduction of wild-type $F$. graminearum radial growth at a concentration of 100 to 500 ng/ml. A similar reduction in wild-type $F$. culmorum radial growth was seen when a CPT concentration of 500 to 1,000 $\mathrm{ng} / \mathrm{ml}$ was included in SNA plates. The radial growth rates of 
$F$. graminearum and $F$. culmorum top 1 gene-deletion mutants and the insertion mutant TB3 were unaffected by the addition of CPT to the SNA medium at all concentrations tested, including the highest concentration of $100 \mu \mathrm{g} / \mathrm{ml}(100,000 \mathrm{ng} / \mathrm{ml})$, thus confirming the absence of any functional TOP1 protein in these strains (Fig. 2).
Wheat ear infection assays.

To investigate further the effect of the TOP 1 gene deletion on $F$. graminearum and $F$. culmorum pathogenicity, susceptible wheat ears were point inoculated with SNA agar plugs of different Fusarium cultures. The four independent $F$. graminearum topl gene-deletion mutants each showed a dramatic reduction
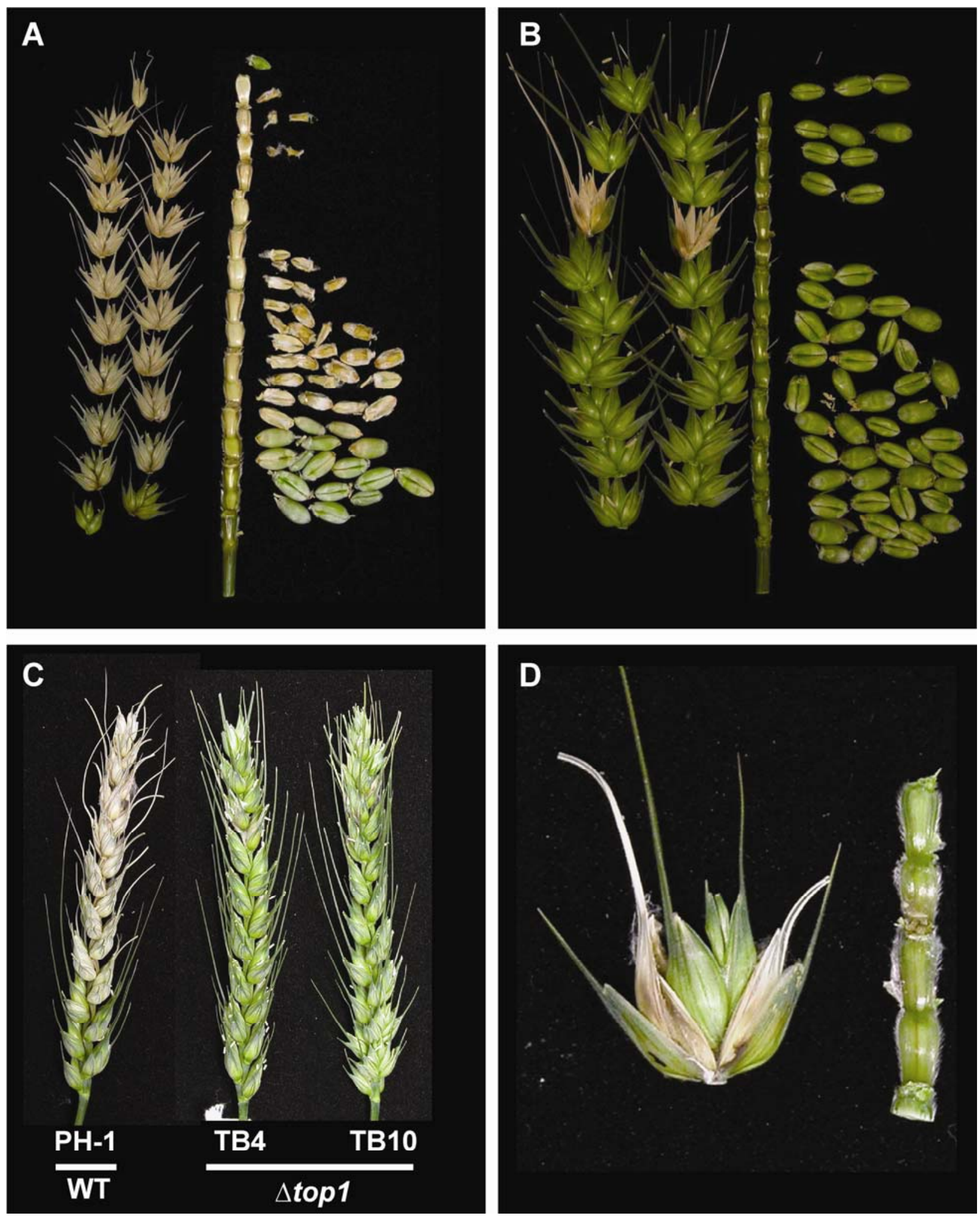

Fig. 1. Inoculated susceptible wheat ears at 20 days post-point inoculation dissected into spikelets, rachis, and grain. A, Fusarium graminearum wild-type control (PH-1). B, TB3 insertion mutant. C, Disease symptoms in wheat ears infected with wild-type PH-1 and two independent top1 gene deletion mutants. D, Dissected spikelet previously inoculated with a top1 gene deletion mutant (TB4) and the adjacent rachis segment. 
in virulence when compared with a wild-type control 20 days postinoculation (dpi) (Fig. 1C; data not shown). At this time point, the wild-type infection had spread from the two inoculated spikelets via the rachis to other spikelets on the wheat ear. The entire ear became infected following inoculations with the ectopic transformants. Dissection of the region around the point of inoculation of the topl mutants revealed that the fungal infection was restricted to the two inoculated florets in each spikelet. Visible symptoms of fungal infection, including browning and bleaching, were restricted to the glumes, palea, and lemma of the inoculated florets. Other florets in the top 1infected spikelets were unaffected by the mutant strains and continued to develop wheat grains (Fig. 1D). The mutant strains also did not grow into the rachides, which remained green and symptomless. Reisolation experiments confirmed that the fungi were not growing asymptomatically in the rachides of inoculated wheat ears.

Similar results were obtained from wheat ear inoculation experiments done with the various $F$. culmorum strains. Macroscopic observation of intact and longitudinal dissected wheat ears (Fig. 3A and B through D) revealed that the wild-type strain UK99 spread from the inoculated spikelets into all the other spikelets via the rachis to cause bleaching throughout the ear. Infections with an ectopic $F$. culmorum transformant (TB16) resulted in wild-type symptoms. The two F. culmorum top1 mutants (TB13 and TB14) showed greatly reduced symptoms and were restricted to the inoculated florets which exhibited browning on the glumes and awn bleaching. The infection was confined to the inoculated floret and did not spread into the rachis, which remained completely green. The topl mutant had not infected the other florets within the inoculated spikelet; these remained green and contained developing grain when harvested 20 days postinfection (Fig. 3D).

To investigate the possibility that the deletion of TOP1 in F. graminearum and $F$. culmorum results in a penetration defect, wounded wheat ears were inoculated with wild-type and top 1 mutant strains. Wheat ears at anthesis were wounded by cutting horizontally through the apical spikelets and rachis. Symptoms of cell death were restricted to the cut edges of the spikelets and rachis in the control SNA-only inoculated ears. Inoculation of wounded ears with the wild-type $F$. graminearum strain $\mathrm{PH}-1$ resulted in the spread of bleaching symptoms to the whole wheat ear as observed during infection assays with intact ears. Two F. graminearum top 1 mutants (TB3 and TB4) colonized the inoculated cut spikelets, and some limited spread of browning down the rachis was observed. However, the $F$. graminearum mutants were unable to spread into the other intact spikelets (Fig. 3E). Symptoms of premature senescence and bleaching of wounded ears were observed in infection assays with wild-type (UK99) and ectopic (TB16) strains of $F$. culmorum. In contrast, the $F$. culmorum topl mutant strains caused only limited browning which did not spread to the base of the inoculated florets. There were also no symptoms of bleaching beyond the cut surfaces of the inoculated rachides (Fig. 3F). Overall, the F. culmorum mutants appeared to be more restricted in invasive growth than the corresponding $F$. graminearum mutants.

\section{Detailed microscopic analysis of the infection biology of the $F$. graminearum top1 mutant in wheat ears.}

The progress of fungal infection was monitored regularly until 14 dpi by taking longitudinal sections of the ear (Fig. 4A through F). By 9 dpi, the wild-type infection had spread beyond the inoculated florets into the neighboring spikelets and the desiccated tissue lacked red autofluorescence, suggesting the absence of chlorophyll. Over the identical time period and inoculation conditions, the $F$. graminearum topl mutant (TB4) infection was limited to the inoculated florets, which showed only discrete patches of browning on the floral brackets. However, the rachis node of the topl mutant-infected spikelet had turned brown and emitted a pale blue to yellow autofluorescence, indicative of the accumulation of phenolic compounds.

Within each floret, the palea is the floral bracket within which the developing wheat grain resides. This structure consists of a thick-walled abaxial surface and a very thin-walled adaxial surface (Fig. 4G and J). By 5 dpi, the wild-type PH-1 hyphae were present throughout the palea in all cell types (Fig. $4 \mathrm{H}$ and $\mathrm{K}$ ). In contrast, the topl mutant hyphae were restricted to the lower parenchyma cells on the adaxial surface and were absent from the vascular bundles (Fig. 4I and L). In response to the top 1 mutant infection, many of the nearby plant cells appeared misshapen and collapsed. There was also substantial

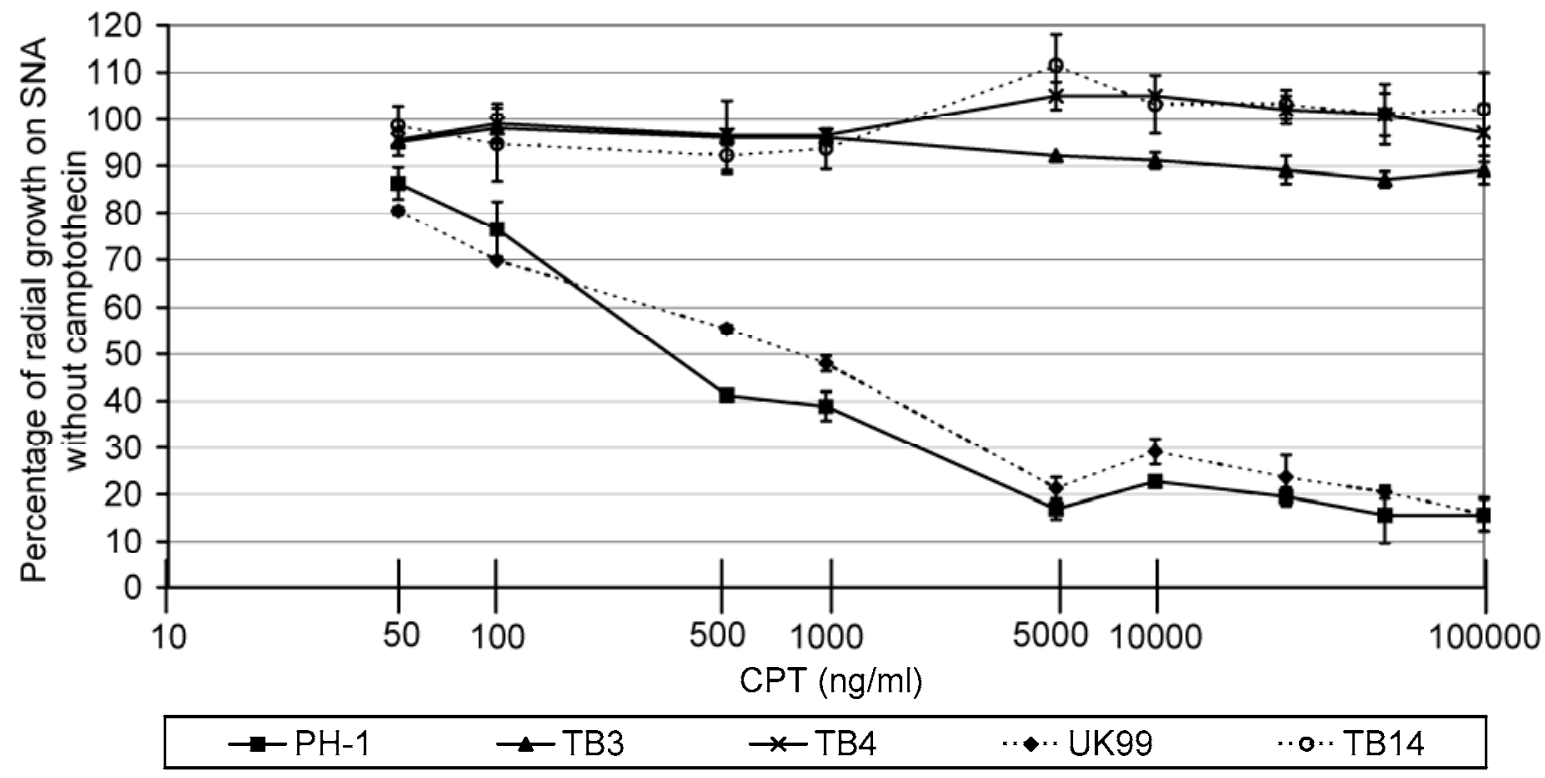

Fig. 2. Effects of camptothecin (CPT) on colony growth of wild-type and top1 mutant Fusarium strains on synthetic nutrient-poor agar (SNA) plates. Error bars are \pm one standard deviation $(n=3)$. Logarithmic scale on the x-axis. PH-1 (Fg wt), TB3 (Fg top1::pHyg1.4), TB4 (Fg $\Delta t o p 1)$, UK99 (Fc wt), TB14 (Fc $\Delta$ top1). 
cell wall deposition. Cryostat sections of mock-inoculated and top1 mutant-infected palea stained with safranin $\mathrm{O}$ and alcian blue gave a strong red coloration solely in the abaxial epidermal cell layer. Cryostat sections of mock-inoculated and top 1 mutant-infected palea initially stained with safranin $\mathrm{O}$ and then counter-stained with alcian blue gave a strong red coloration solely in the abaxial epidermal cell layer, indicative of the presence of lignin polymers (Supplementary Fig. 6A and B). CryoSEM analysis revealed that the top1 mutant-infected palea tissue had lost considerable cellular integrity compared with the mock inoculated control (data not shown).

The development of the necrotic region in the rachis node of the top 1 mutant-infected floret by $7 \mathrm{dpi}$ led to the hypothesis that the progress of the topl mutant hyphae into the rachis was blocked via a host response in this region. Five dpi was the time point chosen for further study because this coincided with the onset of visible autofluorescence at the rachis node. In contrast to the wild-type infection, where abundant intra- and intercellular hyphae were present throughout the tissue examined, no topl mutant hyphae were identified in the serial sections of the entire rachis or rachis node. Despite the absence of topl mutant hyphae, cellular depositions were present throughout the vascular tissue of the rachis node. These were absent from the healthy and wild-type infected rachis node (Fig. 4M through $\mathrm{R})$. The host response in the rachis node was approximately $1,000 \mu \mathrm{m}$ ahead of the top 1 mutant hyphal front which remained confined to the palea. By 9 dpi, numerous dead host cells were present within the tissue surrounding the rachis node but still no topl mutant hyphae were identified in the rachis or rachis node (Supplementary Fig. 7).

\section{Mycotoxin production.}

The capacity of the F. graminearum top 1 mutants to produce trichothecene mycotoxins was tested by gas chromatographymass spectrometry (GC-MS). Two topl mutants (TB3 and TB4), an ectopic transformant (TB6), and the PH-1 wild-type strain were cultured under in vitro deoxynivalenol (DON)inducing conditions in triplicate biological experiments. The
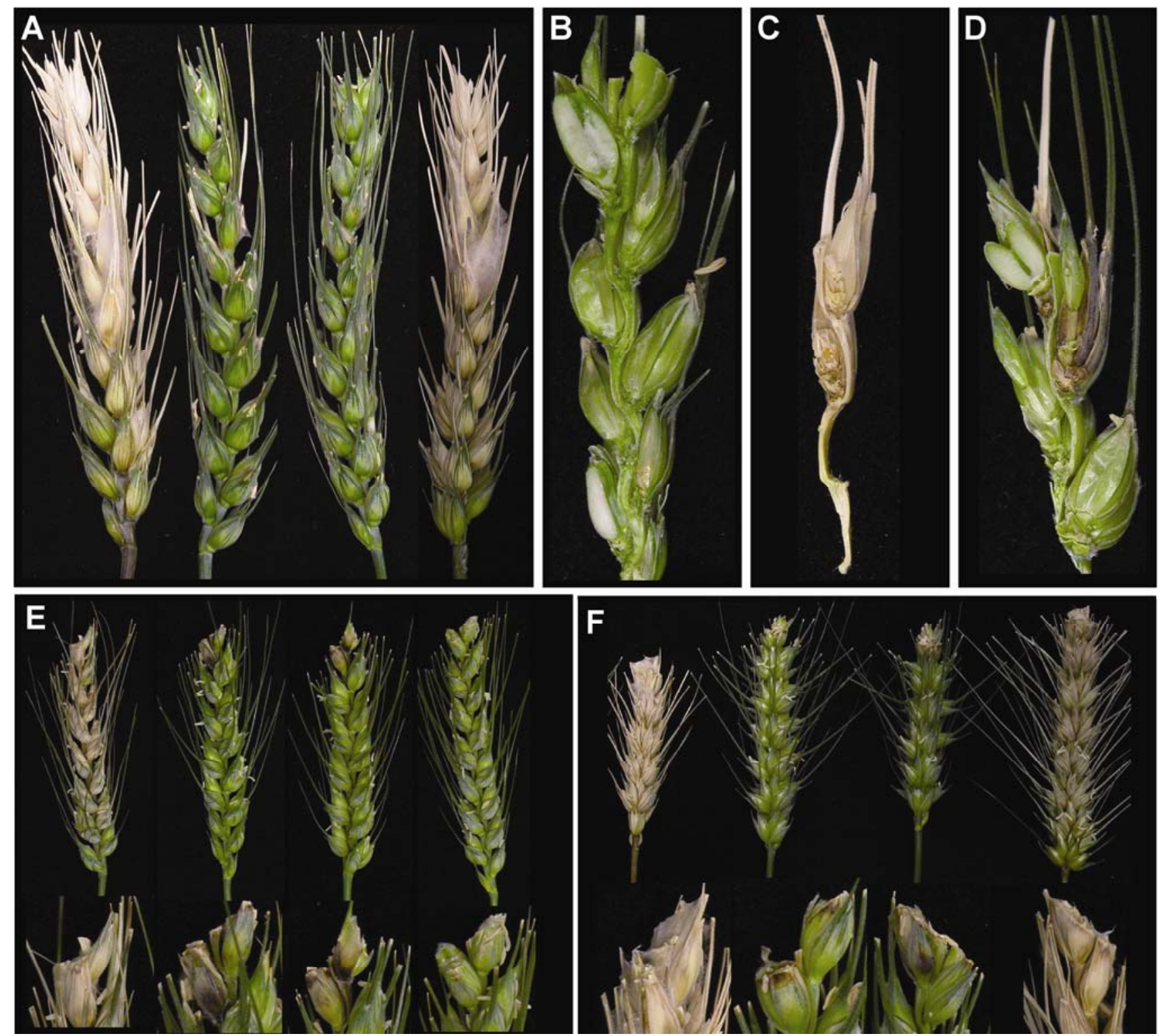

Fig. 3. Susceptible wheat ears inoculated with wild-type and top1 mutants ( 20 days post-point inoculation). A, Left to right: wild-type Fusarium culmorum (UK99), top1 mutants (TB13 and TB14), and an ectopic transformant (TB16). B, Longitudinal dissection of an uninoculated wheat ear. C, Longitudinal dissection of a UK99-infected wheat ear. D, top1 (TB14)-infected wheat ear. E, Wounded wheat ears inoculated with F. graminearum wild-type and top1 mutants. Left to right: PH-1, TB3, TB4, and synthetic nutrient-poor agar control. F, Wounded wheat ears inoculated with F. culmorum wild-type, top1 mutants, and an ectopic transformant. Left to right: UK99, TB13, TB14, and TB16. 
Mock-inoculated
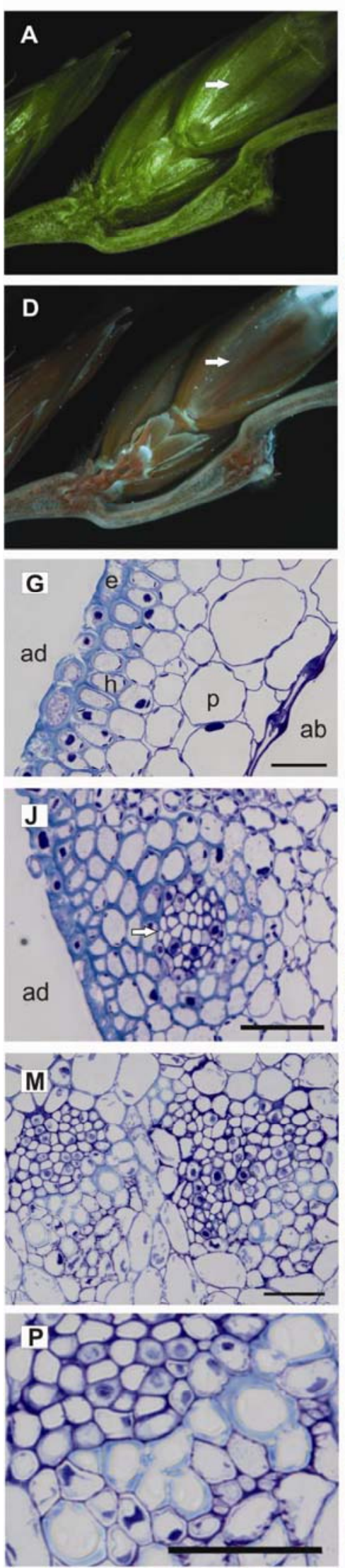

$\mathrm{PH}-1$-inoculated
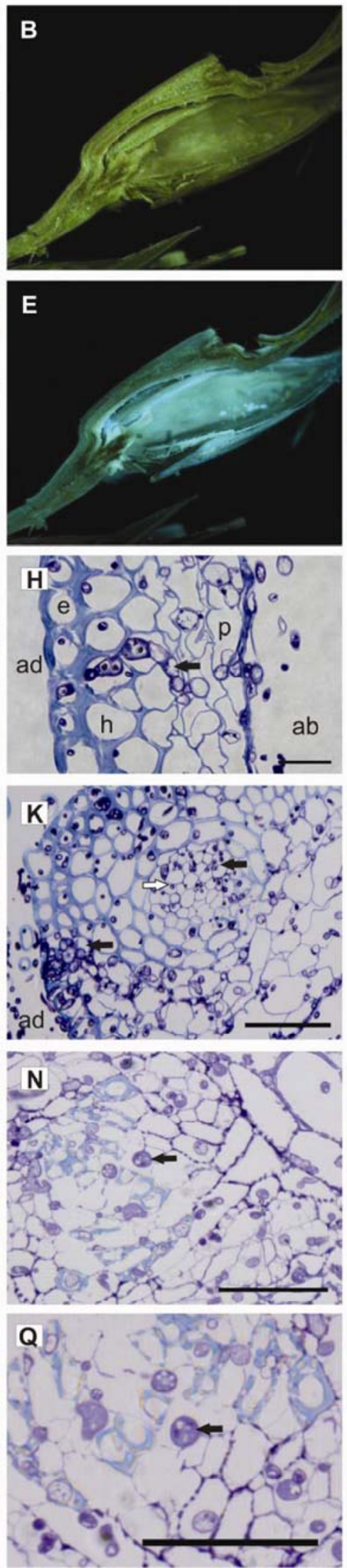

Fgtop1-inoculated
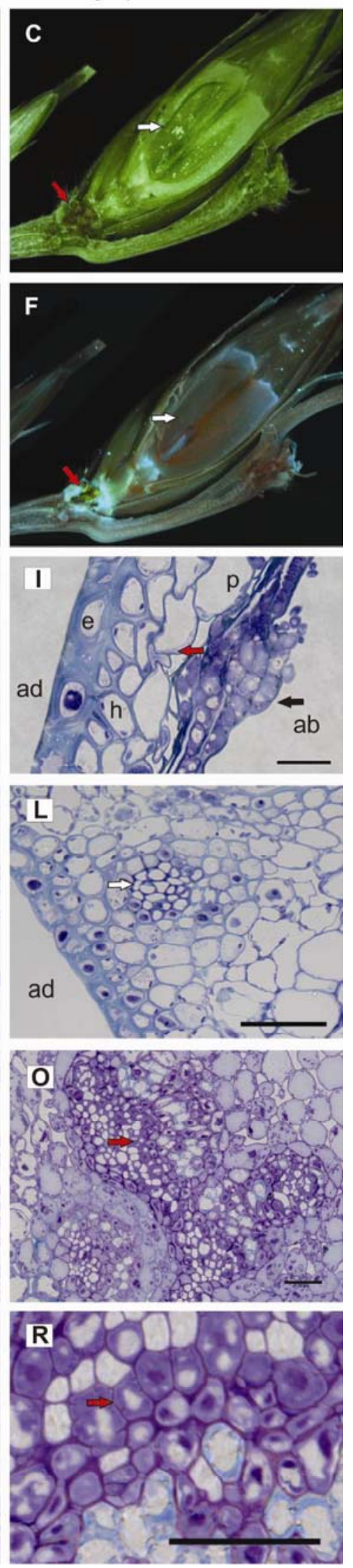

Fig. 4. Detailed microscopic analysis of the infection biology of the Fusarium graminearum topl (TB4) mutant in wheat ears. Sectioned wheat ears were viewed under $\mathbf{A}$ through $\mathbf{C}$, bright-field and $\mathbf{D}$ through $\mathbf{F}$, ultraviolet (UV) illumination. Sections of $\mathbf{G}$ through $\mathbf{L}$, palea tissue and $\mathbf{M}$ through $\mathbf{R}$, rachis nodes were stained with toluidine blue $\mathbf{O}$. A, C, D, and F, White arrows indicate developing wheat grain; J through $\mathbf{L}$, white arrows indicate the phloem. $\mathbf{C}, \mathbf{F}, \mathbf{I}, \mathbf{O}$, and $\mathbf{R}$, Red arrows indicate the location of the responding host cells. Black arrows in various panels locate fungal hyphae. Abbreviations $(\mathrm{G}$ to $\mathrm{L})$ : e $=$ epidermis, $\mathrm{h}=$ hypoepidermis, $\mathrm{p}=$ parenchyma, $\mathrm{ad}=$ adaxial, and $\mathrm{ab}=$ abaxial. 
biomass produced by the four strains grown for 14 days was not significantly different compared with the wild type (data not shown). Extracts from these in vitro liquid cultures were tested for the presence and quantity of DON and 15-acetyldeoxynivalenol (15-ADON) trichothecene mycotoxins. Analyses of variance (ANOVA) revealed there were no statistically significant differences between the concentrations of DON and 15-ADON produced by the four strains tested (Table 1).

\section{In vitro growth phenotypes}

of the $F$. graminearum and $F$. culmorum mutants.

Fungal mycelial growth rates were tested on solid potato dextrose agar (PDA) (nutrient-rich medium) and on SNA (nutrient-poor medium) plates. When grown in the dark, there were no statistically significant differences between the growth of the $F$. graminearum wild-type strain $\mathrm{PH}-1$ and two $F$. graminearum topl transformants at $16^{\circ} \mathrm{C}$ on both media. However, at $28^{\circ} \mathrm{C}$, both of the $F$. graminearum top 1 mutant strains exhibited reduced growth on PDA and increased growth on SNA when compared with the PH-1 wild-type strain (Table 2). However, the small increase in growth observed at $28^{\circ} \mathrm{C}$ on SNA was not associated with any obvious differences between the colony morphologies of the $F$. graminearum topl mutant and wild-type strains. The growth rates of the two independent $F$. graminearum topl mutants were not significantly different. When grown on PDA, the $F$. culmorum wild-type colonies exhibited darker pigmentation and developed more aerial mycelium than the topl mutants. The overall morphology of the $F$. culmorum wild-type and mutant colonies were similar on SNA at $28^{\circ} \mathrm{C}$ and both PDA and SNA at $16^{\circ} \mathrm{C}$ but had reduced radial growth rates (Table 2). However, on PDA at $28^{\circ} \mathrm{C}$, both $F$. culmorum top 1 gene deletion mutants developed a fast-growing fine, near-transparent mycelium that spread rapidly across the surface of the agar medium and produced minimal pigment. In

Table 1. Mycotoxin production in Fusarium graminearum strains $^{\mathrm{a}}$

\begin{tabular}{lcr}
\hline Genotype & DON & \multicolumn{1}{c}{ 15-ADON } \\
\hline Wild type & $2,652( \pm 1,542)$ & $21,506( \pm 7,404)$ \\
top1::pHyg1.4 & $1,833( \pm 1,925)$ & $6,162( \pm 6,915)$ \\
Atop1 (TB4) & $412( \pm 410)$ & $4,192( \pm 5,636)$ \\
Ectopic transformant (TB6) & $1,284( \pm 1,111)$ & $11,700( \pm 9,757)$ \\
\hline
\end{tabular}

${ }^{a}$ Values are the mean parts per billion (ppb) of three biological replicates ( \pm one standard deviation). No statistically significant differences were found between the four strains for each of the two mycotoxins tested in vitro. $\mathrm{DON}=$ deoxynivalenol and $15-\mathrm{ADON}=15$-acetyldeoxynivalenol. contrast, the wild-type strain UK99 developed a slower-growing, densely pigmented mycelium that spread to fill the air space in the petri dish.

This collection of fungal strains was also tested for radial growth on SNA under constant illumination by a combination of near-UV and white light, which induces asexual sporulation (conidiation). No significant differences were seen between the radial growth of $F$. graminearum wild-type and top $1 \mathrm{mu}-$ tant strains growing on SNA under these conditions. However, a statistically significant reduction in the growth of the $\mathrm{F}$. $\mathrm{cul}$ morum topl strain was observed in these conditions when compared with the wild-type UK99 strain incubated in the same conditions (Table 2).

\section{Asexual and sexual sporulation.}

Both $F$. graminearum topl mutants tested retained the ability to produce asexual spores (conidia), although the numbers of spores were less than the wild type. There were no statistically significant differences between the two $F$. graminearum top1 mutants (Table 3). The germination efficiencies of wildtype and mutant conidia were assessed $24 \mathrm{~h}$ after inoculation onto SNA plates. Microscopy of the surface of the SNA plates revealed that $95 \%$ of conidia of both the wild-type and top 1 mutant strains had germinated (data not shown).

The wild-type $F$. culmorum UK99 strain produced significantly more conidia than the wild-type $F$. graminearum $\mathrm{PH}-1$ strain. However, unlike the $F$. graminearum topl mutants which retained the capacity to produce conidia, the $F$. culmorum mutants did not produce any conidia. To investigate

Table 3. Spore production of wild-type and top1 mutant Fusarium strains

\begin{tabular}{lc}
\hline Species, genotype & Spore count $\left(\times \mathbf{1 0}^{\mathbf{4}} \text { conidia per plate }\right)^{\mathbf{a}}$ \\
\hline Fusarium graminearum & $145 \pm 32$ \\
Wild type & $99^{* *} \pm 26$ \\
top1::pHyg1.4 & $97^{* *} \pm 14$ \\
Atop1 (TB4) & \\
F. culmorum & $447 \pm 80$ \\
Wild type & $0.0^{* *} \pm 0.0$ \\
Atop1 (TB13) & $0.0^{* *} \pm 0.0$ \\
Atop1 (TB14) & $483 \pm 18$ \\
Ectopic (TB16) & \\
\hline
\end{tabular}

${ }^{a}$ Values are mean spore counts \pm one standard deviation $(n=6)$. Analysis of variance was used to identify least significant differences at $<1$ and $<5 \%$ levels for each species; $* *$ indicates differences from the wild-type strain at $P<0.01$

Table 2. Diameter of fungal colonies growing on potato dextrose agar (PDA) and synthetic nutrient-poor agar (SNA) in the dark at 16 or $28^{\circ} \mathrm{C}$ for 4 days and under constant illumination with near-UV and white light ${ }^{\mathrm{a}}$

\begin{tabular}{|c|c|c|c|c|c|}
\hline \multirow[b]{4}{*}{ Species, genotype } & \multicolumn{5}{|c|}{ Colony diameter (nm) } \\
\hline & \multicolumn{4}{|c|}{ Incubation temperature $\left({ }^{\circ} \mathrm{C}\right)$} & \multirow{3}{*}{$\begin{array}{c}\text { Sporulation }^{\mathbf{b}} \\
\text { SNA }\end{array}$} \\
\hline & \multicolumn{2}{|c|}{16} & \multicolumn{2}{|c|}{28} & \\
\hline & SNA & PDA & SNA & PDA & \\
\hline \multicolumn{6}{|c|}{ Fusarium graminearum } \\
\hline Wild type & $29.7 \pm 3.6$ & $40.3 \pm 1.1$ & $59.3 \pm 2.8$ & $84.2 \pm 1.4$ & $49.7 \pm 0.6$ \\
\hline top $1:$ :pHyg 1.4 & $28.0 \pm 0.9$ & $40.5 \pm 0.6$ & $65.3 * \pm 3.5$ & $62.8^{* *} \pm 1.5$ & $49.7 \pm 1.5$ \\
\hline Atopl (TB4) & $27.0 \pm 1.6$ & $40.7 \pm 2.0$ & $64.7 * \pm 3.7$ & $61.5^{* *} \pm 2.3$ & $48.0 \pm 2.7$ \\
\hline \multicolumn{6}{|l|}{ F. culmorum } \\
\hline Wild type & $34.8 \pm 2.5$ & $36.5 \pm 3.1$ & $67.0 \pm 0.5$ & $52.8 \pm 2.8$ & $71.7 \pm 3.51$ \\
\hline$\Delta t o p 1$ (ТВ13) & $23.7 * * \pm 1.3$ & $31.2 * * \pm 1.9$ & $48.8 * * \pm 1.8$ & $69.5^{* *} \pm 1.7$ & Not tested \\
\hline$\Delta t o p 1$ (ТВ14) & $23.0^{* *} \pm 1.3$ & $32.2 * * \pm 1.3$ & $47.7 * * \pm 5.1$ & $69.7 * * \pm 1.9$ & $47.7 \pm 1.53^{\mathrm{c}}$ \\
\hline
\end{tabular}

${ }^{a}$ Measurements are mean colony diameters in millimeters \pm one standard deviation $(n=3)$. Values are the mean and average standard deviation from two independent growth tests with three replicates for each test. Analysis of variance with blocking (for the two independent tests) was used to identify least significant differences at $<1$ and $<5 \%$ levels; * indicates differences from the wild-type strain at $0.01<P<0.05$ and $* *$ indicates differences at $P<0.01$.

${ }^{\mathrm{b}}$ Incubation for asexual sporulation.

${ }^{\mathrm{c}} \mathrm{A} t$ test was used to identify a significant difference $(P<0.01)$ between the wild-type and top1 mutant $F$. culmorum strain. No significant differences in growth were observed between the $F$. graminearum strains. 
whether the transformation process per se affected the capacity of transformants to sporulate, an ectopic topl transformant was tested for spore production. There was no significant difference between the sporulation of the ectopic transformant (TB16), which was generated in the same transformation experiment as TB14, and the wild-type F. culmorum strain (Table 3).

The $F$. graminearum top 1 deletion mutant TB4 and the original mutant TB3 were each tested on carrot agar plates for their capacity to develop perithecia. The $\mathrm{PH}-1$ inoculated plates developed many perithecia by day 11 . Both mutants did not produce perithecia on the carrot agar plates at $11 \mathrm{dpi}$. No perithecia or protoperithecia initials were visible after a prolonged incubation period of 24 days. F. culmorum, which does not reproduce sexually, was not tested on carrot agar plates.

\section{DISCUSSION}

Topoisomerase I has been the subject of molecular genetic studies in several pathogenic fungal species which attack plants or animals as well as in nonpathogenic fungal species (Table 4). These Fusarium spp. results represent the first study demonstrating the importance of topoisomerase I in fungal plant pathogenicity. TOPl was identified as a potential $F$. graminearum virulence factor from a forward genetics experiment. This result led to the identification and sequencing of the F. culmorum homologue of TOP1. Characterization of targeted gene deletion strains of $F$. graminearum and $F$. culmorum created in this study verified the importance of TOP1 in plant pathogenesis and sporulation in both species. In addition, a reduction in pigmentation was observed during in vitro culture and CTAB lysis of fungal mycelia from the $F$. graminearum and F. culmorum top 1 mutants. A color variant pigment phenotype was previously observed in cultures of the $U$. maydis top 1 mutant (Gerhold et al. 1994). The $U$. maydis pigment was not identified by Gerhold and associates (1994). The only red pigment produced by $F$. graminearum characterized so far is aurofusarin, a naphthoquinone compound, which is not required for virulence (Malz et al. 2005). The identity of the pigment present at reduced levels in the topl mutants of both Fusarium spp. is not known.

The observation that topoisomerase I is not essential for in vitro growth of Fusarium spp. is consistent with the studies of topl mutants of $U$. maydis (Gerhold et al. 1994), Candida albicans (Jiang et al. 1997), S. pombe (Uemura et al. 1987), and Saccharomyces cerevisiae (Goto and Wang 1985). The topoisomerase I enzyme in eukaryotic organisms, including $S$. cerevisiae and Schizosaccharomyces pombe, has been shown to be involved in uncoiling DNA during transcription and DNA replication (Champoux 2001). Relaxation of DNA supercoils in both eukaryotic and prokaryotic species has been demonstrated to lead to chromatin unfolding and increased transcription (Travers and Muskhelishvili 2007). A study of the human bacterial pathogen Salmonella enterica linked DNA supercoiling with changes in transcription of virulence genes (O'Croinin et al. 2006).

Yeast, when cultured on fermentable carbohydrates, exhibits two different growth phases (diauxic growth) followed by a shift into a stationary phase. Studies with Saccharomyces cerevisiae revealed that, as yeast cells entered the stationary phase from the slow-growth phase, a TOP1-dependent 95\% reduction in the messenger (m)RNA levels of expressed genes occurred. The reduction in mRNA levels was due to a reduction in transcription during the late $\log$ and stationary phases. In contrast, this transcriptional repression did not occur in yeast topl deletion mutant strains (Choder 1991). Differences in the Fusarium cell cycle status would be expected between the invading hyphal front and the mycelium in fully colonized and dead host tissue. In addition, yeast transcriptomic analyses revealed that TOP1 was required for normal transcription of highly transcribed genes during exponential growth in S. cerevisiae. In the same study, the TOP1 protein was a found to be recruited at telomeric and telomere-proximal regions in chromatin immunoprecipitation (ChIP) experiments (Lotito et al. 2008). In F. graminearum, the subtelomeric regions of the genome have already been noted to be enriched for genes specifically expressed in planta (Cuomo et al. 2007).

The reduced invasive growth observed in the top 1 mutantinoculated wheat ears may also reflect a failure to adapt to the different host responses occurring within the developing wheat spikelets. These virulence defects appear to allow the wheat ears to respond by inducing host defenses to restrict the invasive growth of the top 1 mutants. The detailed study of top 1 mutant growth in the inoculated floret revealed that the cells of the wheat palea surrounding the topl hyphae had accumulated substantial cell wall depositions that contained lignin polymers. Therefore, the in-planta-growing topl hyphae would have to cope with activated defense responses. In contrast, during in vitro growth, radial growth rates are unaffected on agar plates because the growth conditions are relatively homogeneous at the hyphal front and the fungus does not encounter host defenses.

The complete lack of colonization of the rachis node by the topl hyphae was not anticipated, considering the extensive macroscopic symptoms always observed in this region of the ear when viewed under either bright light or UV at low magnification. Therefore, the topl hyphae present within the palea may be releasing a diffusible signal or signals which induce host defenses and cell death at a distance. Alternatively, the plant cells in contact with the topl mutant mycelium may have responded to the infection and released a diffusible signal or signals to induce plant cells at a distance to respond. It is currently unclear why only specific cell types, namely the vascular bundles and adjacent cells in the rachis node, have responded while all other cells appear microscopically normal. The deletion in $F$. graminearum of the secreted lipase gene $F G L 1$ led to the induction of plant defense responses and cell death in the rachis (Voigt et al. 2005) but this occurred in all tissues types immediately in advance of the Fusarium hyphae and extended for up to $5 \mathrm{~mm}$. There were no statistically significant differences between the $F$. graminearum strains tested for in vitro DON production in this study. Inoculation experiments with wheat ears from cv. Bobwhite and a tri5 mutant (which encodes an enzyme for the first committed step of DON biosynthesis)

Table 4. Fungal topoisomerase I genes investigated by gene disruption or deletion

\begin{tabular}{lll}
\hline Species & Life style & Reference \\
\hline Saccharomyces cerevisiae & Nonpathogen & Goto and Wang 1985 \\
Schizosaccharomyces pombe & Nonpathogen & Uemura et al. 1987 \\
Candida albicans & Human pathogen & Jiang et al. 1997 \\
Cryptococcus neoformans & Human pathogen & Del Poeta et al. 1999b \\
Ustilago maydis & Plant pathogen & Gerhold et al. 1994 \\
Fusarium graminearum & Plant pathogen & This study \\
F. culmorum & Plant pathogen & This study \\
\hline
\end{tabular}


in the PH-1 background resulted in the development of eyeshaped lesions on the glumes of infected wheat ears (Cuzick et al. 2008). In contrast, the topl mutant infections always caused full spikelet bleaching under the identical conditions. Therefore, it would be interesting in the future to create a topl tri5 double mutant and investigate whether the interaction phenotype is altered in the absence of DON mycotoxin production.

The capacity to sporulate asexually was reduced in the $F$. graminearum topl mutants and was abolished in the $F$. culmorum top 1 mutants. The wild-type strain of $F$. graminearum readily developed perithecia (sexual spore structures) on plates of carrot agar. In contrast, no perithecia or protoperithecia were observed on plates inoculated with the $F$. graminearum topl mutants. Without the topoisomerase I enzyme, the Fusarium mutants are likely to be unable to regulate the transcriptional changes required for perithecial development. In S. cerevisiae, a top3 mutant was unable to produce ascospores. Analysis of the stage at which spore production was blocked revealed that the top3 mutant was unable to undergo reductional division during meiosis (Gangloff et al. 1999). The TOP1 and TOP3 proteins are structurally unrelated in both yeast and Fusarium spp. However, it would be interesting to investigate at a molecular level whether the Fusarium TOP1 protein has a role in meiosis that has been assigned to TOP3 in yeast. The topl mutants of $C$. albicans and $U$. maydis were not tested for either asexual or sexual sporulation defects. However, a haploid $S$. cerevisiae topl mutant strain was successfully crossed with a TOPl wild-type strain to give viable haploid progeny (Thrash et al. 1985). F. graminearum is a homothallic fungus. It is possible that topl mutant strains have lost female fertility, the ability to mate or develop perithecial structures. Further experiments are needed to investigate the possibility that top 1 strains would be able to form viable perithecia when crossed with a TOP1 wild-type strain.

The topoisomerase I protein is a well-characterized target for the cytotoxic alkaloid camptothecin, a specific toxin of eukaryotic topoisomerase I (Hsiang et al. 1985). In this study, camptothecin was demonstrated to be toxic to wild-type strains of both $F$. culmorum and $F$. graminearum but, as expected, was nontoxic to the topl mutant strains. Camptothecin was shown to be toxic to the Fusarium spp. by specifically targeting the TOP1 protein. Topoisomerase I has been considered as a potential target for chemical control of the human pathogens C. albicans (Fostel et al. 1996) and Cryptococcus neoformans (Del Poeta et al. 1999a). The concentrations of camptothecin required for a $50 \%$ reduction in the radial growth (EC50) of wild-type Fusarium strains were similar to the EC50 values previously reported for Magnaporthe oryzae and Penicillium digitatum $\left(0.2\right.$ to $\left.1 \mu \mathrm{g} \mathrm{ml}^{-1}\right)$. However, the minimum inhibitory concentrations of camptothecin for wild-type $S$. cerevisiae and $C$. neoformans strains have been reported in the range of 100 to $500 \mu \mathrm{g} / \mathrm{ml}$ (Supplementary Table 1). The differences in camptothecin susceptibility between species are likely to be due to differences in the efficiency of camptothecin entry into fungal cells and the efficiency of efflux transporters to remove camptothecin. The importance of TOP1 in pathogenicity of Fusarium spp. on wheat ears indicates that the TOP1 protein may be a suitable target for chemical control. The importance of the TOP1 protein for sexual sporulation of $F$. graminearum and asexual sporulation of $F$. culmorum also means that a fungicide targeting TOP1 could be effective for the control of Fusarium spp. sporulation. Sporulation is a very important part of the Fusarium spp. life cycle because this monocyclic disease requires spores to be present as inoculum during wheat anthesis (Parry et al. 1995).

This is the first study which connects topoisomerase 1 enzyme function to plant pathogenesis by a microorganism. For both $F$. graminearum and $F$. culmorum, the lack of topoisom- erase 1 enzyme activity causes severe reductions in the ability of fungal mycelium to colonize wheat ear tissues post penetration. In the future, it will be informative to determine whether topoisomerase 1 function is required for the pathogenesis of other Fusarium spp. which colonize nonfloral tissues and noncereal species. For example, $F$. oxysporum infects numerous dicotyledonous plant species via the roots and then colonizes systemically via the vascular tissue. Similarly, the role of topoisomerase 1 in the plant pathogenesis of other fungal species that colonize either leaves, roots, stems, or fruit or cause systemic infections of cereal and noncereal host species would be interesting to explore.

\section{MATERIALS AND METHODS}

All the oligonucleotide primers used in this study are detailed in Supplementary Table 2.

\section{Fungal strains and in vitro growth test conditions.}

One $F$. graminearum strain and three $F$. culmorum strains were studied. F. graminearum strain PH-1 (NRRL 31084) was used for the genome sequencing project at the BROAD institute (Cuomo et al. 2007) and is readily transformable. F. culmorum UK99 (formerly named 98WW4.5fc) was used in transformation experiments. This strain was isolated from wheat grain harvested at Rothamsted Research in 1998 (Dawson et al. 2004). Two other strains, F97/7 and F98/11, were used for sequencing of the TOP1 gene. Both strains were provided by B. Hollins, RAGT, Cambridge, U.K. F97/7 was isolated from Louth, U.K. in July 1997 and F98/11 was isolated from Slate Hall Farm, Barhill, Cambridgeshire, U.K. in July 1998.

$F$. graminearum and $F$. culmorum strains were routinely cultured on 9-cm SNA plates (Urban et al. 2002). PDA (Oxoid, Basingstoke, Hampshire, U.K.) was prepared by the manufacturer's instructions. Production of perithecia was induced on carrot agar as previously published (Trail and Common 2000). Conidiation was induced by incubating SNA and PDA plates at room temperature and under constant illumination from one near-UV tube (Phillips TLD 36W/08) and one white-light tube (Phillips TLD 36W/830HF).

Growth rate tests were initiated by inoculating the center of 9-cm SNA or PDA plates with 5-mm agar plugs cut from the growing edge of fungal colonies maintained on SNA plates. Plates were sealed with parafilm (Alcan Packaging, Bristol, U.K.) and placed in dark incubators maintained at either 16 or $28^{\circ} \mathrm{C}$. The diameters of fungal colonies were measured $4 \mathrm{dpi}$. Two independent growth rate tests were performed with three replicates for each strain tested.

The Fusarium strains used and created in this study are detailed in Supplementary Table 3.

\section{Trichothecene mycotoxin induction in vitro and quantification.}

To induce mycotoxin production in fungal cultures, a twostage culture protocol was followed (McCormick et al. 2004) with slight modifications. Second-stage toxin-induction cultures were grown for 14 days at $25^{\circ} \mathrm{C}$ and $100 \mathrm{rpm}$ in the dark. Fungal mycelium was harvested by filtration through $8.0-\mu \mathrm{m}$ Millipore membrane filters (Fisher Scientific, Loughborough, Leicestershire, U.K.) and freeze dried to constant weight. Mycotoxin content in filtrates was measured using GC-MS analysis based on a protocol by Tacke and Casper (1996) using services provided by the National Centre for Plant and Microbial Metabolomics (Harpenden, U.K.). Briefly, culture medium $(630 \mu \mathrm{l})$ was added to $3.37 \mathrm{ml}$ of acetonitrile (Fisher Scientific, U.K.) and $1.3 \mu \mathrm{g}$ of DOM-1 internal standard (Romer Labs $\mathrm{GmbH}$, Tulln, Austria) and extracted for $60 \mathrm{~min}$ at room tem- 
perature. Extracts were column purified as described, derivatized, and injected into a 7890 Gas Chromatograph coupled to a 5975C Inert MSD (Agilent Technologies, Santa Clara, CA, U.S.A.) fitted with a Zebron Guardian ZB-5 column. Electron ionization mass spectra were acquired using selected ion monitoring for diagnostic ions for DON, 3-ADON, 15-ADON, NIV, and DOM-1 (internal standard). Peak areas for the mycotoxins in Fusarium spp. supernatant samples and in nine standard curve samples covering a range from $50 \mathrm{ppb}$ to $25 \mathrm{ppm}$ were calculated using the software Masslynx (Micromass, Manchester, U.K.).

\section{Camptothecin growth tests.}

To investigate the susceptibility of Fusarium strains to the topoisomerase specific toxin camptothecin (Hsiang et al. 1985), 9-cm SNA plates were made with varying concentrations of camptothecin. A stock of camptothecin (Sigma-Aldrich, Gillingham, Dorset, U.K.) dissolved in dimethyl sulfoxide (DMSO) at $40 \mathrm{mg} / \mathrm{ml}$ was prepared. Different volumes of the stock solution were added to molten SNA agar immediately prior to plate pouring. Extra DMSO was also added to the molten agar to maintain a final DMSO concentration in the SNA plates of $0.25 \%$, regardless of the volume of CPT solution added. Each plate was made with $15 \mathrm{ml}$ of SNA. Three replicates were done for each strain at each concentration tested. Plates were inoculated with fungal strains for growth tests within $24 \mathrm{~h}$ of the plate pouring, sealed with cling film, and incubated at $28^{\circ} \mathrm{C}$ for 4 days before being assessed for radial growth.

\section{Cloning of PCR products.}

DNA fragments were amplified with HotstarTaq DNA polymerase (Qiagen, Basel, Switzerland). PCR products were cloned using a TA-cloning kit (Invitrogen, Paisley, U.K.). Ligation of DNA fragments was done with T4 DNA ligase following the manufacturer's instructions (MBI Fermentas, York, U.K.). TOP10 chemically competent Escherichia coli cells were transformed with ligation mixtures following the manufacturer's instructions (Invitrogen).

\section{Sequencing.}

Sequencing reactions were done with ABI Big Dye terminators V1.1 (Applied Biosystems, Warrington, U.K.). Reactions were done in a total volume of $10 \mu \mathrm{l}$ in $200-\mu \mathrm{l}$ PCR tubes. Sequencing reaction products were purified using an ethanol/sodium acetate method recommended by Applied Biosystems to remove unincorporated dye terminators. Dried extension products were sent to the University of Oxford for sequencing on an ABI Prism 3730xl DNA Analyser (DNA Sequencing Facility, University of Oxford, Oxford). Raw DNA sequences were trimmed manually and assembled into contigs with the Contig Express program (Vector NTI V9.1.0; Invitrogen).

\section{Random insertional mutagenesis and TOP1 gene replacements.}

The library of random insertion $F$. graminearum transformants was created by transformation of wild-type $\mathrm{PH}-1$ protoplasts with linearized pHYG1.4 (Supplementary Fig. 8). TOP1 gene-deletion strains of $F$. graminearum and $F$. culmorum were created by targeted gene replacement with the $H P H$ hygromycin phosphotransferase gene. Split-marker gene-deletion constructs were created using methods previously established for $F$. graminearum gene deletion (Catlett et al. 2003; Cuzick et al. 2008).

An 827-bp 5' upstream region of the FgTOPl gene was amplified from PH-1 genomic DNA with primers TOP5'sense and TOP5'anti. A 799-bp 3' downstream region of the FgTOP1 gene was amplified from $\mathrm{PH}-1$ genomic DNA with primers
TOP3'sense and TOP3'anti. The PCR products were cloned using an Invitrogen Original TA cloning kit following the manufacturer's instructions (Invitrogen). The plasmids carrying the PCR products were named pCR3' and pCR5'. Sequencing of pCR3' and pCR5' identified cloned flanks that did not contain differences from the genome sequence. An 822-bp 5 " upstream region of the FCTOPI gene was amplified from UK99 genomic DNA with primers TOP5'sense and TOP5'anti. An 805-bp 3' downstream region of the FCTOPl gene was amplified from UK99 genomic DNA with primers FCTOP3'+ and TOP3'anti. The PCR products were cloned using an Invitrogen Original TA cloning kit following the manufacturer's instructions (Invitrogen). The plasmids carrying the PCR products were named pCRfc3' and pCRfc5'. Sequencing of pCRfc3' and $\mathrm{pCRfc}^{\prime}$ was done to identify cloned flanks that did not contain differences from the F. culmorum TOP 1 sequence.

Plasmid pHYTOP3' was created by ligating a HindIII-XhoI fragment of pCR3', containing the FgTOP1 3' flank, with the pHY vector cut with HindIII and XhoI. Plasmid pYGTOP5' was created by ligating a $S a c I-X b a I$ fragment of pCR5', containing the FgTOP1 5' flank, with the pYG vector cut with SacI and XbaI (Supplementary Fig. 9). Plasmid pHYfc3' was created by ligating a HindIII-XhoI fragment of pCRfc3', containing the FCTOPl 3' flank, with the pHY vector cut with HindIII and XhoI. Plasmid pYGfc5' was created by ligating a SacI-XbaI fragment of pfcCR5', containing the FcTOP1 5' flank, with the pYG vector cut with SacI and XbaI.

For transformations with plasmid DNA, $5 \mu \mathrm{g}$ of the $3^{\prime}$ plasmid was digested with XhoI and SacII and mixed with $5 \mu \mathrm{g}$ of 5 ' plasmid digested with SacI and ClaI. The split-marker DNA mixes were used to transform protoplasts of the PH-1 strain using the standard protocol previously described (Urban et al. 2003).

\section{DNA gel blot.}

DNA gel blots were used to quantify the number of copies of plasmids inserted into the genomic DNA of fungal transformants using a standard protocol (Sambrook et al. 1989). The restriction enzymes EcoRV, NcoI, and XhoI were used individually to digest fungal genomic DNA. DNA gel blots were probed by hybridizing radiolabeled PCR products following the manufacturer's protocol (Rediprime II random prime DNA Labeling System; Amersham Biosciences, Little Chalfont, U.K.).

\section{Plasmid rescue.}

The flanking regions of plasmids integrated into fungal genomic DNA during protoplast transformation were recovered by plasmid rescue. A plasmid rescue technique described by Kuspa and Loomis (1992) was modified and applied to isolating the inserted plasmids from the genomic DNA of the $F$. graminearum transformants. In all, $10 \mu \mathrm{l}$ containing $10 \mu \mathrm{g}$ of genomic DNA was digested with either EcoRV or XhoI restriction enzymes. The purified DNA from the two digestion reactions were diluted and ligated in individual 500- $\mu$ reactions. The EcoRV or XhoI digestion-ligation mixtures ( $2 \mu \mathrm{l}$ each) were used to transform chemically competent $E$. coli cells to give 16 and 42 colonies, respectively.

\section{Wheat ear inoculation and disease assessment.}

Wheat plants of the spring cv. Bobwhite were used for ear inoculations using a previously published protocol (Urban et al. 2002). Disease symptoms were assessed visually by counting the number of bleached spikelets every 4 days from 4 to 20 dpi. A Nikon Coolpix 5700 digital camera was used for photography of the infected wheat ears (Nikon UK Ltd., Kingston upon Thames, U.K.). 
Wheat ears were dissected at 20 dpi by removing spikelets and sectioning the rachis with a scalpel. Spikelets, grain, and rachis sections were surface sterilized by immersing in $40 \%$ bleach (sodium hypochlorite, $2 \%$ available chlorine), washing with sterile distilled water, and plating on PDA plates. The presence of fungus in wheat tissue was determined by the absence or presence of fungal growth from the plant material into the PDA media.

\section{Hand sectioning and microscopy of the wheat ear.}

Wheat ears inoculated with $\mathrm{PH}-1$, the $F$. graminearum top 1 mutant (TB4), or sterile water were sampled regularly until 14 dpi. Freehand longitudinal sections that cut through the center of all spikelets, dividing the ear in two, were prepared using a clean scalpel. Sectioned ears were observed under bright-field and ultraviolet light (excitation, $360 \mathrm{~nm}$ and barrier filter, 420 $\mathrm{nm}$ ) on a Leica MZFL11 stereomicroscope.

\section{Preparation of the wheat ear for light microscopy.}

The inoculated wheat ears were sampled 5 dpi. The rachis node of the inoculated spikelet and palea of the inoculated floret were excised. Tissue samples were fixed individually for 16 $\mathrm{h}$ with $4 \%$ paraformaldehyde and $2.5 \%$ glutaraldehyde (Sigma-Aldrich) in $0.1 \mathrm{M}$ Sorensen's phosphate buffer $\left(\mathrm{NaH}_{2} \mathrm{PO}_{4}: \mathrm{Na}_{2} \mathrm{HPO}_{4}, \mathrm{pH} 7.2\right)$, then washed three times with 0.05 M Sorensen's buffer and once with sterile water. Samples were subsequently dehydrated in a graded ethanol series, embedded in hard-grade LR White (TAAB), and polymerized at $60^{\circ} \mathrm{C}$ for $24 \mathrm{~h}$. Transverse semithin $1-\mu \mathrm{m}$ sections, for light microscopy, were cut with a glass knife on an ultramicrotome (Reichert-Jung, Depew, NY, U.S.A.). Sections were collected on glass slides and dried on a hot plate set at $40^{\circ} \mathrm{C}$. After staining with aqueous $0.1 \%$ toluidine blue $\mathrm{O}$ in $1 \%$ sodium tetraborate, $\mathrm{pH}$ 9, sections were examined and imaged using a Zeiss Axiophot.

For histochemical analyses, the palea of the inoculated floret was excised, then fixed with a cold solution of $75 \%$ ethanol (vol/vol) and $25 \%$ acetic acid (vol/vol). The fixed tissues were infiltrated with a $15 \%$ sucrose (wt/vol) solution, individually embedded in Tissue Tek OCT (Sakura Finetek, Torrance, CA, U.S.A.), and frozen in liquid nitrogen. The embedded tissues were subsequently transferred to a Leica Cryostat CM1850 set at $-15^{\circ} \mathrm{C}$. The frozen tissues were cut into 10 - $\mu$ m-thick sections by the cryostat, collected on glass slides, and dried on a hot plate set at $40^{\circ} \mathrm{C}$. Sections were stained to detect lignin polymers with aqueous $1 \%$ Safranin O for $2 \mathrm{~min}$, washed with deionized water, counterstained with aqueous $1 \%$ Alcian blue for $2 \mathrm{~min}$, and then finally washed with deionized water. Stained sections were examined and imaged using a Zeiss Axiophot.

\section{CryoSEM analyses.}

The palea of the inoculated floret was excised using a sterile blade and forceps, mounted onto a cryo stub using OCT compound (Sakura Finetek), and plunge frozen in liquid nitrogen. Samples were transferred under vacuum to the Gatan Alto 2100 cryo chamber stage maintained at $-180^{\circ} \mathrm{C}$, where fracturing, sublimation for $1 \mathrm{~min}$ at $-95^{\circ} \mathrm{C}$, and then gold coating was performed for $90 \mathrm{~s}$. The samples were transferred to the Jeol LV6360 scanning electron microscope chamber maintained at $-150^{\circ} \mathrm{C}$ for examination.

\section{Statistics.}

The one-sample $t$ test was used to identify statistically significant differences between two populations. One-way ANOVA with blocking was used to identify least significant differences between more than two populations. The computer program Genstat (version 9.2; VSN International, Oxford), was used for these statistical calculations. The Microsoft Excel computer program was used for calculating means, standard deviations, and $P$ values for the $\chi^{2}$ test.

\section{Gene prediction and sequence phylogeny.}

Gene prediction was done with the FGENESH program available on the Softberry website. FGENESH is a Hidden Markov Model based prediction program which has been optimized for $F$. graminearum and was used by the BROAD Institute for predicting genes in the $\mathrm{PH}-1$ genome sequence. Amino acid alignment and molecular phylogeny was done with the MEGA program (version 3.1). Amino acid alignments were constructed with the CLUSTALW algorithm. Molecular phylogeny was done with the neighbor-joining method and confidence values were calculated by the bootstrap test with 1,000 replications.

\section{ACKNOWLEDGMENTS}

We thank R. Lowe for help with sample preparation for mycotoxin analysis; N. Hawkins for technical assistance with the GC-MS analysis; I. Pearman and J. Franklin for maintenance of controlled environment facilities; A. van den Meene and J. Devonshire for advice and training for the microscopy done in the Bioimaging facility at Rothamsted Research; and N. Pain, J. Rudd, and J. Lucas for their numerous helpful inputs throughout this study. All experiments at Rothamsted Research involving $F$. graminearum $\mathrm{PH}-1$ and the topl mutants were conducted in biological containment facilities under FERA license number PHL 174E/5543. Rothamsted Research receives grant-aided support from the Biotechnology and Biological Sciences Research Council (BBSRC) of the U.K. This study was additionally supported by BBSRC industrial CASE studentships provided by Syngenta.

\section{LITERATURE CITED}

Catlett, N. L., Lee, B. N., Yoder, O. C., and Turgeon, B. G. 2003. Splitmarker recombination for efficient targeted deletion of fungal genes. Fungal Genet. News1. 50:9-11.

Champoux, J. J. 2001. DNA topoisomerases: Structure, function, and mechanism. Annu. Rev. Biochem. 70:369-413.

Choder, M. 1991. A general topoisomerase I-dependent transcriptional repression in the stationary phase in yeast. Genes Dev. 5:2315-2326.

Cuomo, C. A., Gueldener, U., Xu, J. R., Trail, F., Turgeon, B. G., Di Pietro, A., Walton, J. D., Ma, L. J., Baker, S. E., Rep, M., Adam, G., Antoniw, J., Baldwin, T., Calvo, S., Chang, Y. L., DeCaprio, D., Gale, L. R., Gnerre, S., Goswami, R. S., Hammond-Kosack, K., Harris, L. J., Hilburn, K., Kennell, J. C., Kroken, S., Magnuson, J. K., Mannhaupt, G., Mauceli, E., Mewes, H. W., Mitterbauer, R., Muehlbauer, G., Munsterkotter, M., Nelson, D., O’Donnell, K., Ouellet, T., Qi, W. H., Quesneville, H., Roncero, M. I. G., Seong, K. Y., Tetko, I. V., Urban, M., Waalwijk, C., Ward, T. J., Yao, J. Q., Birren, B. W., and Kistler, H. C. 2007. The Fusarium graminearum genome reveals a link between localized polymorphism and pathogen specialization. Science 317:1400-1402.

Cuzick, A., Urban, M., and Hammond-Kosack, K. 2008. Fusarium graminearum gene deletion mutants mapl and tri5 reveal similarities and differences in the pathogenicity requirements to cause disease on Arabidopsis and wheat floral tissue. New Phytol. 177:990-1000.

Dawson, W., Jestoi, M., Rizzo, A., Nicholson, P., and Bateman, G. L. 2004. Field evaluation of fungal competitors of Fusarium culmorum and $F$. graminearum, causal agents of ear blight of winter wheat, for the control of mycotoxin production in grain. Biocontrol Sci. Technol. 14:783-799.

Del Poeta, M., Chen, S. F., Von Hoff, D., Dykstra, C.C., Wani, M. C., Manikumar, G., Heitman, J., Wall, M. E., and Perfect, J. R. 1999a. Comparison of in vitro activities of camptothecin and nitidine derivatives against fungal and cancer cells. Antimicrob. Agents Chemother. 43:2862-2868.

Del Poeta, M., Toffaletti, D. L., Rude, T. H., Dykstra, C. C., Heitman, J., and Perfect, J. R. 1999b. Topoisomerase I is essential in Cryptococcus neoformans: Role in pathobiology and as an antifungal target. Genetics 152:167-178.

Fostel, J., Montgomery, D., and Lartey, P. 1996. Comparison of responses of DNA topoisomerase I from Candida albicans and human cells to four new agents which stimulate topoisomerase-dependent DNA 
nicking. FEMS (Fed. Eur. Microbiol. Soc.) Microbiol. Lett. 138:105111 .

Gangloff, S., de Massy, B., Arthur, L., Rothstein, R., and Fabre, F. 1999. The essential role of yeast topoisomerase III in meiosis depends on recombination. EMBO (Eur. Mol. Biol. Organ.) J. 18:1701-1711.

Gerhold, D., Thiyagarajan, M., and Kmiec, E. B. 1994. The topoisomerase I gene from Ustilago maydis: Sequence, disruption and mutant phenotype. Nucleic Acids Res. 22:3773-3778.

Goto, T., and Wang, J. C. 1985. Cloning of yeast TOP1, the gene encoding DNA topoisomerase I, and construction of mutants defective in both DNA topoisomerase I and DNA topoisomerase II. Proc. Natl. Acad. Sci. U.S.A. 82:7178-7182.

Hirschman, J. E., Balakrishnan, R., Christie, K. R., Costanzo, M. C., Dwight, S. S., Engel, S. R., Fisk, D. G., Hong, E. L., Livstone, M. S., Nash, R., Park, J., Oughtred, R., Skrzypek, M., Starr, B., Theesfeld, C. L., Williams, J., Andrada, R., Binkley, G., Dong, Q., Lane, C., Miyasato, S., Sethuraman, A., Schroeder, M., Thanawala, M. K., Weng, S., Dolinski, K., Botstein, D., and Cherry, J. M. 2006. Genome Snapshot: A new resource at the Saccharomyces Genome Database (SGD) presenting an overview of the Saccharomyces cerevisiae genome. Nucleic Acids Res. 34:D442-D445.

Hsiang, Y. H., Hertzberg, R., Hecht, S., and Liu, L. F. 1985. Camptothecin induces protein-linked DNA breaks via mammalian DNA topoisomerase I. J. Biol. Chem. 260:14873-14878.

Jiang, W. D., Gerhold, D., Kmiec, E. B., Hauser, M., Becker, J. M., and Koltin, Y. 1997. The topoisomerase I gene from Candida albicans. Microbiology 143:377-386.

Kuspa, A., and Loomis, W. F. 1992. Tagging developmental genes in Dictyostelium by restriction enzyme-mediated integration of plasmid DNA. Genetics 89:8803-8807.

Lotito, L., Russo, A., Chillemi, G., Bueno, S., Cavalieri, D., and Capranico, G. 2008. Global transcription regulation by DNA topoisomerase I in exponentially growing Saccharomyces cerevisiae cells: Activation of telomere-proximal genes by TOP1 deletion. J. Mol. Biol. 377:311-322.

Malz, S., Grell, M. N., Thrane, C., Maier, F. J., Rosager, P., Felk, A., Albertsen, K. S., Salomon, S., Bohn, L., Schafer, W., and Giese, H. 2005. Identification of a gene cluster responsible for the biosynthesis of aurofusarin in the Fusarium graminearum species complex. Fungal Genet. Biol. 42:420-433.

McCormick, S. P., Harris, L. J., Alexander, N. J., Ouellet, T., Saparno, A., Allard, S., and Desjardins, A. E. 2004. Tri1 in Fusarium graminearum encodes a P450 oxygenase. Appl. Environ. Microbiol. 70:20442051.

O'Croinin, T., Carroll, R. K., Kelly, A., and Dorman, C. J. 2006. Roles for DNA supercoiling and the Fis protein in modulating expression of virulence genes during intracellular growth of Salmonella enterica serovar Typhimurium. Mol. Microbiol. 62:869-882.

O'Donnell, K., Kistler, H. C., Tacke, B. K., and Casper, H. H. 2000. Gene genealogies reveal global phylogeographic structure and reproductive isolation among lineages of Fusarium graminearum, the fungus causing wheat scab. Proc. Natl. Acad. Sci. U.S.A. 97:7905-7910.

Parry, D. W., Jenkinson, P., and McLeod, L. 1995. Fusarium ear blight (scab) in small-grain cereals-a review. Plant Pathol. 44:207-238.

Redinbo, M. R., Stewart, L., Kuhn, P., Champoux, J. J., and Hol, W. G. J. 1998. Crystal structures of human topoisomerase I in covalent and noncovalent complexes with DNA. Science 279:1504-1513.

Sambrook, J., Fritsch, E., and Maniatis, T. 1989. Molecular Cloning: A Laboratory Manual. Cold Spring Harbor Laboratory Press, Plainview, NY, U.S.A.

Tacke, B. K., and Casper, H. H. 1996. Determination of deoxynivalenol in wheat, barley, and malt by column cleanup and gas chromatography with electron capture detection. J. AOAC Int. 79:472-475.

Thrash, C., Bankier, A. T., Barrell, B. G., and Sternglanz, R. 1985. Cloning, characterization and sequence of the yeast DNA topoisomerase I gene. Proc. Natl. Acad. Sci. U.S.A. 82:4374-4378.

Trail, F., and Common, R. 2000. Perithecial development by Gibberella zeae: A light microscopy study. Mycologia 92:130-138.

Travers, A., and Muskhelishvili, G. 2007. A common topology for bacterial and eukaryotic transcription initiation? EMBO (Eur. Mol. Biol. Organ.) Rep. 8:147-151.

Uemura, T., Morino, K., Uzawa, S., Shiozaki, K., and Yanagida, M. 1987. Cloning and sequencing of Schizosaccharomyces pombe DNA topoisomerase I gene, and effect of gene disruption. Nucleic Acids Res. 15:9727-9737.

Urban, M., Daniels, S., Mott, E., and Hammond-Kosack, K. 2002. Arabidopsis is susceptible to the cereal ear blight fungal pathogens Fusarium graminearum and Fusarium culmorum. Plant J. 32:961-973.

Urban, M., Mott, E., Farley, T., and Hammond-Kosack, K. 2003. The Fusarium graminearum MAP1 gene is essential for pathogenicity and development of perithecia. Mol. Plant Pathol. 4:347-359.

Voigt, C. A., Schafer, W., and Salomon, S. 2005. A secreted lipase of Fusarium graminearum is a virulence factor required for infection of cereals. Plant J. 42:364-375.

Waalwijk, C., Kastelein, P., de Vries, I., Kerenyi, Z., van der Lee, T., Hesselink, T., Kohl, J., and Kema, G. 2003. Major changes in Fusarium spp. in wheat in the Netherlands. Eur. J. Plant Pathol. 109:743-754.

Wang, J. C. 2002. Cellular roles of DNA topoisomerases: A molecular perspective. Nat. Rev. Mol. Cell Biol. 3:430-440.

\section{AUTHOR-RECOMMENDED INTERNET RESOURCES}

Broad Institute website: www.broad.mit.edu

The Institute of Bioinformatics and Systems Biology MIPS (Munich Information Center for Protein Sequences) website: mips.gsf.de/

The MIPS Fusarium graminearum Genome database: mips.gsf.de/genre/proj/fusarium

Softberry website: www.softberry.com 